\title{
Heat Shock Protein 70 Secretion by Neonatal Tracheal Tissue During Mechanical Ventilation: Association With Indices of Tissue Function and Modeling
}

\author{
EUMING CHONG, KEVIN C. DYSART, AARON CHIDEKEL, ROBERT LOCKE, THOMAS H. SHAFFER, \\ AND THOMAS L. MILLER
}

\begin{abstract}
Department of Pediatrics [E.C., K.C.D., A.C., T.H.S., T.L.M.], Jefferson Medical College, Philadelphia, Pennsylvania 19107; Nemours Research Lung Center [K.C.D., A.C., T.H.S., T.L.M.], Alfred I. duPont Hospital for Children, Wilmington, Delaware 19803; Department of Neonatology [R.L.], Christiana Care Hospital, Newark, Delaware 19718; Departments of Physiology and Pediatrics [T.H.S.], Temple University School of Medicine, Philadelphia, Pennsylvania 19140
\end{abstract}

\begin{abstract}
Mechanical ventilation (MV) of the neonatal airway alters mechanical properties and activates tissue-modeling pathways. Heat shock protein (HSP70) is a marker of tissue injury and modulates inflammation, which may influence subsequent pulmonary tissue modeling by matrix metalloproteinases (MMPs). HSP70 secretion is up-regulated in MV airway tissues and associated with changes in airway elasticity and secretion of MMPs. Proximal tracheal segments were isolated in 13 newborn lambs and were either MV for $4 \mathrm{~h}$ or SHAM. At baseline and hourly, tracheal segments were flushed and tracheal elasticity was determined. Tracheal wash fluid was assayed for HSP70 by ELISA and for MMPs by substrate zymography. HSP70 secretion increased from baseline to a peak at $1 \mathrm{~h}$ in both groups $(p<0.01)$, greater in the MV group $(p<0.05)$, and returned to baseline values by $2 \mathrm{~h}$. This response was in contrast to the progressive decrease in tracheal elasticity $(p<0.05)$. The HSP70 elevation pattern was noted in MMP-2, but beyond $1 \mathrm{~h}, \mathrm{MMP}-2$ returned to baseline values in MV group but remained elevated in SHAM $(p<0.05)$. HSP70 secretion is associated with the degree of biophysical tracheal injury as well as the time course of MMP-2 secretion by tracheal tissues. (Pediatr Res 65: 387-391, 2009)
\end{abstract}

$\mathrm{I}$ nfants develop significant trauma to the large conducting airway as a result of mechanical ventilation (MV) (1). In the fetal and neonatal periods, there are developmental changes in the structural and functional properties of the airways increasing bronchial distensibility (2-5). The resulting tracheal trauma is due to distending a relatively distensible airway while attempting to inflate a relatively noncompliant lung (6). The biophysical injury induced by MV (6-10) results in a molecular inflammatory response that contributes to biologic trauma with respect to tissue proteolysis and ultimately tissue remodeling (11-13).

In a recent model to quantify the functional impact of MV on the airway developed by our group, we noted that airway mechanical properties are markedly altered following only short periods of MV. Moduli of elasticity, representing dynamic air-

Received June 17, 2008; accepted November 5, 2008.

Correspondence: Euming Chong, M.D., Department of Pediatrics, Tulane University School of Medicine, 1430 Tulane Avenue, New Orleans, Louisiana 70112; e-mail: echong@tulane.edu

This study was funded through Nemours, an NIH COBRE grant 1 P20 RR020173-01 (The Center for Pediatric Research).

This work was performed at the Alfred I. duPont Hospital for Children of the Nemours Foundation. way elasticity whereby a greater value represents less elasticity, can be determined for the neonatal lamb trachea in real-time (14). Data from these studies show that over time, airways exposed to MV lose elasticity compared with SHAM controls (15).

Matrix metalloproteinases (MMPs) are believed to contribute to normal tissue modeling as well as the progression of airway injury and chronic disease (11-13). MMPs contribute to the reparative process by degrading basement membrane components and modulating inflammation (16) and therefore can be a contributing factor to changes in the structure and function of ventilated airways. MMP-2 and MMP-9, specifically, are implicated in having an important role in airway development and injury (17-19) and therefore can be used as a marker of airway injury/remodeling.

Heat shock protein (HSP) 70 is secreted in response to injury by different tissues $(20,21)$. If induced before an injury, HSP is believed to attenuate the degree of inflammation by stabilizing inhibitory kappa B factor (22-26). Inhibitory kappa B factor plays a major role in stabilizing nuclear factor kappa $\mathrm{B}(\mathrm{NF} \kappa \mathrm{B})$ activation. Upon $\mathrm{NF} \kappa \mathrm{B}$ activation, downstream genes regulating inflammatory mediators will be activated and hence activate the inflammatory cascade $(23,27)$. Therefore, we reason out that HSP-70 secretion may be induced during airway trauma by MV as a marker of injury and possible attenuate the degree of injury.

The objective of this study is to determine the relationship between ventilation-induced airway injury and the secretion of HSP-70 and MMPs. We hypothesize that HSP-70 secretion will be up-regulated in airway tissues secondary to MV and this will correspond to changes in expression of MMPs 2 and 9.

\section{METHODS}

Experimental design. Newborn lambs between 1 and $4 \mathrm{~d}$ old $(n=13$; $3.3 \pm 1.2 \mathrm{~d} ; 3.8 \pm 1.2 \mathrm{~kg}$ ) were anesthetized and instrumented as shown in

\footnotetext{
Abbreviations: A:L, active to latent ratio; au, arbitrary unit; ERK, extracellular signal-regulated kinase; ETT, endotracheal tube; $\mathbf{F i O}_{2}$, fraction of inspired oxygen; Fr, French; HSP, heat shock protein; ID, internal diameter; JNK, jun N-terminal kinase; KAX, ketamine/azepromazine/xylazine; MAP, mitogen-activated protein; MMPs, matrix metalloproteinases; MV, mechanical ventilation; NF $\boldsymbol{\kappa} \mathbf{B}$, nuclear factor kappa B; PEEP, positive end expiratory pressure; PIP, positive inspiratory pressure
} 


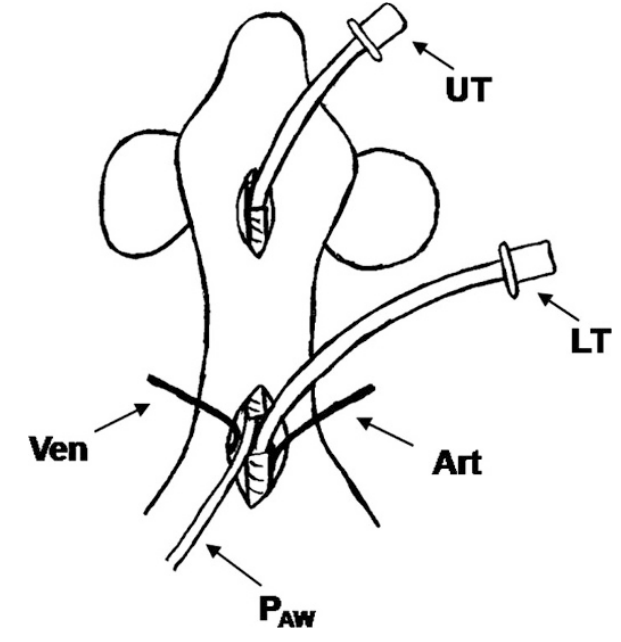

Figure 1. Schematic drawing of the surgical preparation. An innervated, perfused tracheal segment was isolated between caudal and rostral surgical sites. A lower endotracheal tube (LT) was placed into the distal trachea to allow for spontaneous breathing while arterial (Art) and venous (Ven) catheters provided access for anesthesia, maintenance fluid and arterial sampling and pressure monitoring. The isolated tracheal segment was instrumented with an upper endotracheal tube (UT) to expose the segment to mechanical ventilator pressure waveforms.

Figure 1. Animals were allowed to breathe spontaneously through a lower endotracheal tube (ETT) and were not subjected to MV from the lower ETT. The experimental procedures are applied to the isolated, perfused, and innervated tracheal segment via the upper ETT. The isolated tracheal segment used for analysis is the area between both ETT. This model allows the tracheal segment studied to be isolated and that the known inflammatory effects of ventilation on lung would not have a confounding influence on the airway outcomes. Following instrumentation, animals were randomized to either pressure-limited, time-cycled MV $(n=7)$, or $\operatorname{SHAM}(n=6)$. Measurements of physiologic stability and airway functional parameters were made at baseline and hourly for $4 \mathrm{~h}$; arterial plasma and airway wash fluid was collected at each measurement point.

Animal preparation. All animal procedures in this study were approved by the Life Science Center Animal Care and Use Committee, Department of Biomedical Research, Nemours, and were in accordance with National Institutes of Health guidelines. Lambs were anesthetized initially with two 1 $\mathrm{mL} / \mathrm{kg}$ intramuscular injections, separated by $10 \mathrm{~min}$, of an anesthesia cocktail (ketamine, $23 \mathrm{mg} / \mathrm{kg}$; azepromazine, $0.1 \mathrm{mg} / \mathrm{kg}$; and xylazine, $0.05 \mathrm{mg} / \mathrm{kg}$ [KAX]) adapted from previously described protocols $(28,29)$. Before instrumentation, the region of the lamb's neck covering the trachea was shaved to remove the bulk of the hair, and then hair removal cream (Nair; Carter-Horner Corp., Mississauga, ON, Canada) was applied to make the neck region hair free.

Local anesthesia $(4 \mathrm{mg} / \mathrm{kg} 0.5 \%$ lidocaine $\mathrm{HCl})$ was injected into the skin and soft tissues around caudal and rostral surgical sites as shown in Figure 1. As previously described $(14,15)$, a double tracheotomy was performed at the caudal site, which was located just above the notch of the sternum where the trachea enters the thorax. At this site, the distal trachea was intubated with a 3.5-mm internal diameter (ID) ETT (Hi-Lo Jet Tube; Mallincrodkt, St. Louis, $\mathrm{MO}$ ) to allow for continued spontaneous breathing. The distal end of the proximal trachea was cannulated with a saline-filled catheter (five French $[\mathrm{Fr}]$ ) attached to a pressure transducer; the end of the proximal trachea was ligatured around the catheter to provide a seal to contain gas during ventilator cycles and saline during pressure-volume and ultrasound measurements. The proximal end of the proximal trachea (the isolated segment) was intubated through the rostral surgical site, just distal to the larynx, with a 3.0-mm ID endotracheal tube, which was ligatured into the trachea to prevent gas and saline leaks.

For venous access and arterial blood sampling, respectively, 5 or $8 \mathrm{Fr}$ umbilical catheters were inserted into the external jugular vein and carotid artery through the caudal surgical site. Subsequent anesthesia was maintained with i.v. infusion of KAX at $0.4 \mathrm{~mL} / \mathrm{kg} / \mathrm{h}$ or as needed. Maintenance fluid was provided by a continuous venous infusion of $5 \%$ dextrose solution at a rate of $6 \mathrm{~mL} / \mathrm{kg} / \mathrm{h}$. Arterial blood pressure was monitored by attaching the arterial catheter to a standard pressure transducer via a bedside patient monitor (Model M1175A, Hewlett Packard), and electrodes were placed for ECG monitoring. Throughout the protocol, the animal's rectal temperature was monitored and maintained at $37-40^{\circ} \mathrm{C}$ on a radiant warmer bed (Resuscitaire; Hill-Rom Air-Shields, Hatboro, PA). Following instrumentation, physiologic stability of the animal was confirmed by analysis of arterial blood chemistry (Stat profile; Nova Biomedical, Waltham, MA), ECG, and blood pressure monitoring, and then the isolated tracheal segment was exposed to MV pressure cycles or randomized to SHAM.

Pressure cycles in the MV group were delivered by a neonatal ventilator (Sechrist Neonatal ventilator, Sechrist Industries, Anaheim, CA) for $4 \mathrm{~h}$ at the following settings: peak inspiratory pressure (PIP) $=35 \mathrm{~cm} \mathrm{H}_{2} \mathrm{O}$, positive end expiratory pressure $\left(\right.$ PEEP) $=5 \mathrm{~cm} \mathrm{H}_{2} \mathrm{O}$, flow rate $=10 \mathrm{~L} / \mathrm{min}$, frequency $=$ $40 \mathrm{cycles} / \mathrm{min}$ with inspiratory time $=0.30 \mathrm{~s}$, and fraction of inspired oxygen $\left(\mathrm{FiO}_{2}\right)=0.21$. The higher PIP was used to ensure physical injury was produced in the tracheal segment (14). The other ventilator parameters applied are used commonly in the clinical settings.

At baseline and each subsequent measurement period, the isolated tracheal segment was flushed with normal saline at room temperature, and $5 \mathrm{~mL}$ was collected to be assayed for HSP-70 and MMPs. The collected tracheal wash fluid was centrifuged at $5^{\circ} \mathrm{C}$ and $18,000 \times \mathrm{g}$ for $20 \mathrm{~min}$ to remove debris before storage at $-70^{\circ} \mathrm{C}$. While saline filled, the tracheal segment was assessed for the static pressure-volume relationship and static/dynamic phase ultrasound imaging. Pressure-volume measurements and ultrasound imaging were performed as described in a previous paper by our group $(14,15)$. A high frequency ultrasound system, Vevo 770 High-Resolution Imaging System (VisualSonics, Toronto, Canada), was used to measure tracheal wall thickness and resting segment volumes. Tracheal wall thickness was measured for both posterior and anterior walls, representing the muscle and cartilaginous walls, respectively. Resting segment volumes were derived by multiplying crosssectional area by the segment length. After each measurement set, the saline in the tracheal segment was flushed out with air so that the airway would be gas filled throughout the duration of the protocol.

Following the $4 \mathrm{~h}$ measurements, an IV bolus of $1 \mathrm{~mL} / \mathrm{kg} \mathrm{KAX}$ was administered to achieve deep sedation before the isolated tracheal segment was harvested. At the time of harvest, the isolated tracheal segment length was measured as the distance between ligatures while the segment was still situated in vivo. Euthanasia was then achieved by thoracotomy and pulmonary exsanguination. In total, each animal was under sedation for approximately $5 \mathrm{~h}$.

Measurement of tracheal elasticity in vivo. Methodology and results for in vivo static and dynamic elasticity from these studies was previously reported $(14,15)$. Briefly, static airway pressure-volume relationships were constructed by first filling the isolated tracheal segment with normal saline and allowing the pressure within to equilibrate with the ambient condition. A two-way stopcock was attached to the distal catheter and $0.2 \mathrm{~mL}$ aliquots of saline was injected into the closed tracheal segments in $15 \mathrm{~s}$ intervals until a pressure $\leq 80 \mathrm{~cm} \mathrm{H}_{2} \mathrm{O}$ was achieved, the saline was then withdrawn in the same manner. The resultant pressure profiles associated with the step volume increments were recorded and injected volume units were normalized to resting segment volume. Bulk modulus $(K)$ was calculated as the slope of the pressure-volume curves obtained at each interval.

In ventilated animals, the relationship between tangential wall stress and strain of the trachea was determined during dynamic ventilator pressure loading. Bulk and elastic moduli represent the amount of force (stress) to achieve a degree of deformation (strain). The trachea normally has some degree of elasticity, but our data demonstrate that over time more force is needed to distend the airway. In this regard, the airways are losing elasticity in response to ventilator stress whereby the enlarging ID is associated with the breakdown of elastic components and airway distention is accomplished through stretch of the nonelastic structural components. Bulk modulus measures the volumetric adjustments of the trachea resulting from changes in the airway elastance, measured globally. The Young's modulus derivation accounts for dynamic tissue properties such as inertia and viscoelastic resistance.

Ultrasound imaging provided real-time cross-sectional images at the exact moments where pressure waves peaked and at end expiratory pressure. Stress-strain relationships were constructed where wall stress was a function of ventilatory pressure, luminal diameter and wall thickness, and strain was the associated change in diameter. Young's modulus was adapted to the trachea model as the slope of the stress-strain relationship at each interval.

MMP analysis by substrate zymography. Substrate zymography was used to quantify the relative abundance of both the physiologically active and latent forms of MMP-2 and MMP-9. Before analysis, lung tissue was homogenized in a lysis buffer containing a nonmetalloprotease inhibitor cocktail (Sigma Chemical, St. Louis, MO). Loading buffer was added directly to tracheal wash samples, and equal volumes of each sample were loaded into gels for electrophoresis. Protein was separated in $10 \%$ acrylamide gels containing $1 \mathrm{mg} / \mathrm{mL}$ gelatin (Sigma Chemical, St. Louis, MO) according to previously described methods $(11,29)$. Following electrophoresis, SDS was eluted by washing the gels in $2.5 \%$ Triton-X-100; then the gels were incubated for $18 \mathrm{~h}$ at $37^{\circ} \mathrm{C}$ in incubation buffer containing $50 \mathrm{mM}$ Tris-HCl, pH 7.5, $5 \mathrm{mM}$ calcium chloride, and $0.01 \mathrm{mM}$ 
zinc chloride. Gels were subsequently stained with Coomassie brilliant blue R250 and scanned to a digital image for analysis.

Densitometric analysis of the images was performed using Scion Image software (Scion Corp., Frederick, MD) to determine pixel values for the expression of each sample. Relative quantification in arbitrary units (au) of all MMP bands was accomplished by running a standard curve of a common sample on all gels. The total quantity of each MMP was derived by adding the raw pixel values for the active and latent bands from each lane before extrapolation of the au value from the standard curve. A ratio of the quantity of active (A) to latent (L) forms for each relevant MMP (A:L ratio) was calculated for each sample as the ratio of raw pixel values.

HSP-70 quantification. HSP-70 levels in isolated tracheal segment tissue homogenates and airway wash aliquots were measured using a commercially available HSP70 ELISA Kit (StressXpress; Assay Designs Corporation, Ann Arbor, MI). Airway wash fluid aliquots were lyophilized and reconstituted to $10 \times$ concentrates for HSP-70 detection. All standards and samples were assayed in duplicates, and all samples were diluted to fall within the detection range of this assay. The assay's sensitivity is $500 \mathrm{pg} / \mathrm{mL}$. Interassay and intraassay coefficients of variance is $<10 \%$. HSP-70 samples from tracheal tissue were standardized to total protein concentration and samples from airway wash fluid were standardized to surface area of the isolated tracheal segment.

Statistical analysis. All time-dependent parameters were analyzed using a general linear model analysis of variance (ANOVA) with Bonferroni post hoc tests where applicable. With the exception of elastic modulus, time-dependent parameters were analyzed for main group effects and group by time interaction using two-way ANOVA. All time-dependent parameters were evaluated for group dependent time effects using one-way ANOVA. Tissue content of HSP-70 and MMPs (only at $4 \mathrm{~h}$ time point) were analyzed by $t$ test. Significance was accepted at $p \leq 0.05$.

\section{RESULTS}

Physiologic stability. As previously reported, animals tolerated the protocol with normal physiology, and there were no group differences in vital signs or physiologic parameters (15). All animals displayed a modest respiratory acidosis that was constant throughout the protocol. $\mathrm{Hb}$ saturation remained above $80 \%$ in all animals and heart rate remained constant.

Tissue content of HSP and MMPs. Tracheal tissues was harvested at the end of the 4-h ventilation and homogenized to analyze for presence of HSP-70 as well as MMP-2 and 9. HSP-70 was detected in both SHAM and ventilated tracheal tissue but no difference was found between these two groups

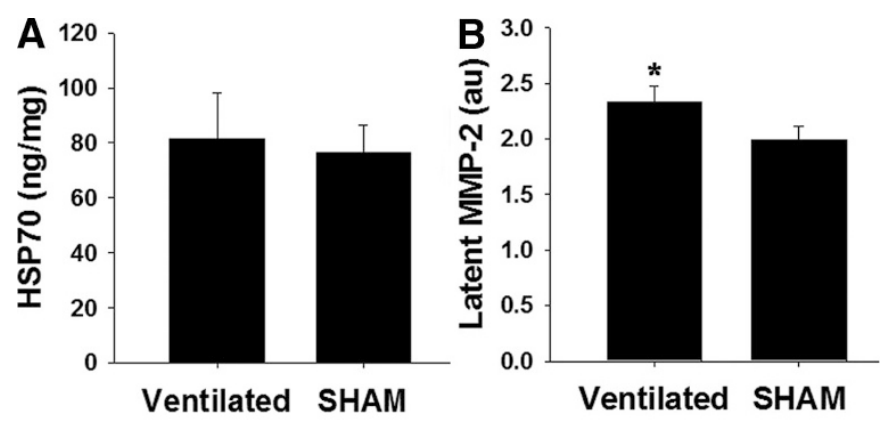

Figure 2. HSP-70 and latent MMP-2 content in tracheal tissue harvested after $4 \mathrm{~h}$ of MV. HSP-70 $(A)$ was detected in both ventilated and SHAM tracheal tissues, but was not different between groups. MMP-2 was also detected in tracheal tissue, and in its latent, pro form $(B)$ was greater in ventilated trachea. * greater than SHAM $(p<0.05)$.
(Fig. 2A). MMP-2 and 9 were detected in tracheal tissues in both their latent and active forms. Latent MMP-2 was significantly more abundant in the ventilated trachea $(p<0.05$; Fig. $2 B)$. There were no differences in the other parameters. Data for all MMP parameters are presented in Table 1.

HSP and MMP secretion. HSP-70 concentration was detected in concentrated airway wash fluid from both groups at baseline and each subsequent time point. In each group, HSP-70 secretion was elevated at $1 \mathrm{~h}$ (Fig. 3), with a greater elevation in the ventilated group as determined by a significant interaction between group and time $(p<0.05)$. HSP-70 secretion then returned to baseline values by $2 \mathrm{~h}$.

Both MMP-2 and 9 were found predominantly in their latent form. Active, latent, and total MMP-2 secretion (Fig. 4) was elevated at $1 \mathrm{~h}$. Beyond $1 \mathrm{~h}$, total and latent MMP-2 secretion (Fig. 4A,C) returned to baseline values in the ventilated group only, resulting in a difference from SHAM values $(p<0.05)$ that remained elevated. Total and latent MMP-9 (Fig. 5A, $C$ ) increased over time in the SHAM group only to produce a main effect for group $(p<0.05)$ by $4 \mathrm{~h}$. There were no group differences in active MMP-2 or MMP-9.

In vivo airway function. Data for the bulk and Young's moduli of elasticity are summarized in Figure 6. Analysis of bulk modulus corrected for percent change from baseline (Fig. $6 A$ ) revealed significant effects for group and time. By $4 \mathrm{~h}$, bulk modulus values for ventilated tracheae were greater than SHAM tracheae $(p<0.01)$ and greater than baseline values $(p<0.05)$. Bulk modulus remained unchanged in the SHAM animals. Analysis of elastic modulus (Fig. 6B), representing the dynamic stress-strain relationships in the ventilated animals only, revealed a time effect $(p<0.05)$ where values were greater by $4 \mathrm{~h}$. These data were discussed in detail in by our group in prior papers $(14,15)$.

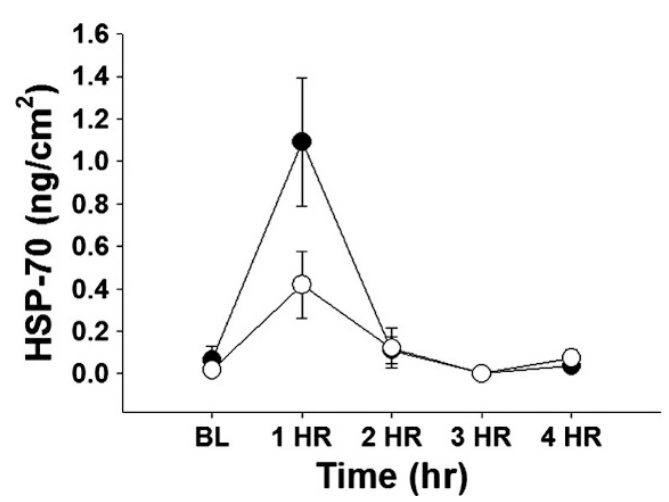

Figure 3. Time dependent changes in HSP-70 secretion into the airway lumen during MV or SHAM. HSP-70 concentration in airway wash fluid increases to a peak at $1 \mathrm{~h}$ for both groups then returns to baseline values. Peak HSP-70 secretions was more robust in the ventilated group (O) compared with the SHAM animals $(\bigcirc)$, associated with a significant interaction for group and time $(p<0.05)$.

Table 1. Tracheal tissue content of MMPs

\begin{tabular}{|c|c|c|c|c|c|c|}
\hline & Latent MMP-2 & Active MMP-2 & Total MMP-2 & Latent MMP-9 & Active MMP-9 & Total MMP-9 \\
\hline Ventilated & $2.33 \pm 0.14^{*}$ & $1.91 \pm 0.12$ & $2.48 \pm 0.22$ & $0.88 \pm 0.18$ & $0.75 \pm 0.34$ & $1.11 \pm 0.15$ \\
\hline SHAM & $1.99 \pm 0.12$ & $1.74 \pm 0.10$ & $2.13 \pm 0.20$ & $1.43 \pm 0.55$ & $0.67 \pm 0.28$ & $1.67 \pm 0.52$ \\
\hline
\end{tabular}

Data are expressed as mean \pm SEM.

$* p<0.05$ compared with SHAM. 

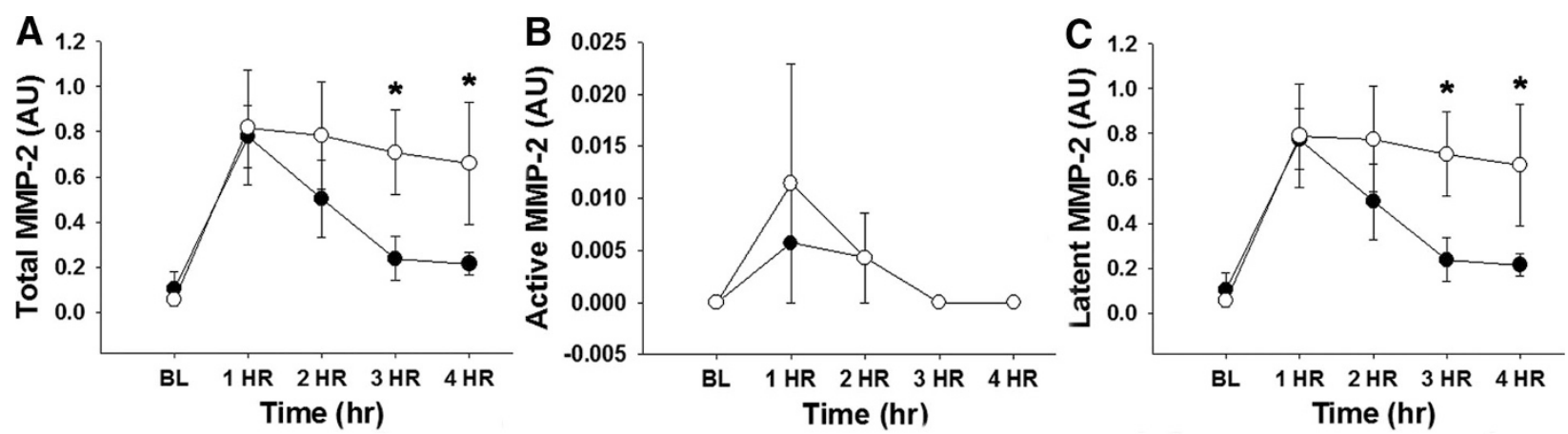

Figure 4. Time dependent changes in total, active and latent MMP-2 secretion into airway lumen during MV or SHAM. Total MMP-2 secretion (A) spiked in both ventilated $(\bigcirc)$ and SHAM $(\bigcirc)$ groups at $1 \mathrm{~h}$, and subsequently returned to baseline values in the ventilated group resulting in a difference from SHAM by $3 \mathrm{~h}$. The MMP-2 found in the active form $(B)$ was not different between groups, whereas the latent MMP-2 $(C)$ followed in the same trend as the total MMP-2 revealing a group difference by $3 \mathrm{~h} . *$ difference between ventilated and SHAM trachea at current time point $(p<0.05)$.
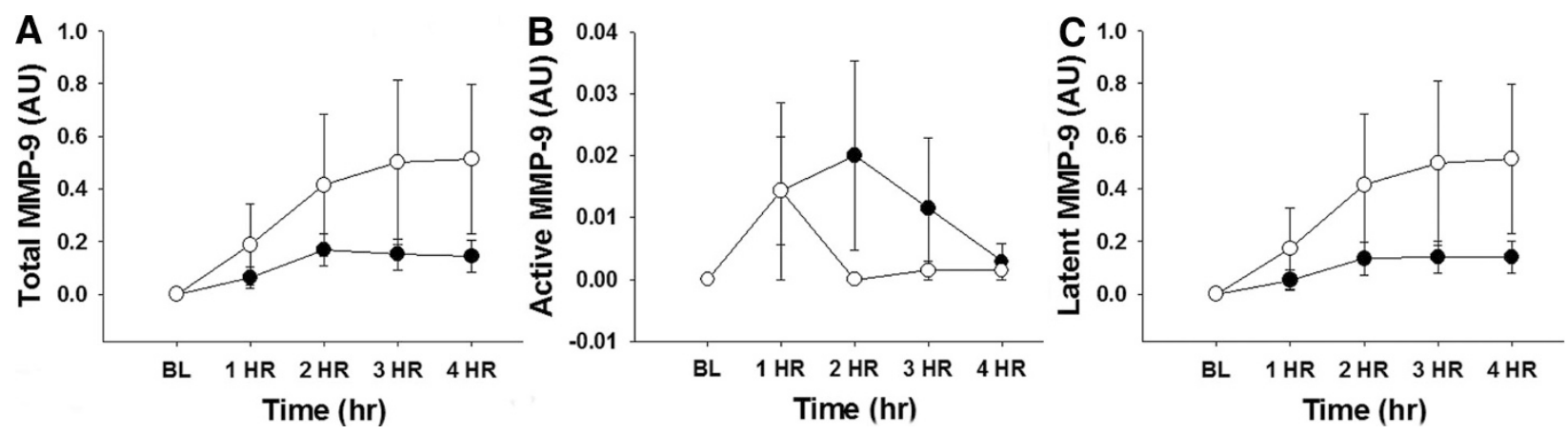

Figure 5. Time dependent changes in total, active and latent MMP-9 secretions into airway lumen during MV or SHAM. Total MMP-9 (A) concentration in airway wash trended higher in the SHAM animals $(\bigcirc)$ than for ventilated $(-)$, but this did not reach significance. Active $(B)$ and latent $(C)$ form of MMP-9 were not different between groups, although the latent form trended the same as total MMP-9.
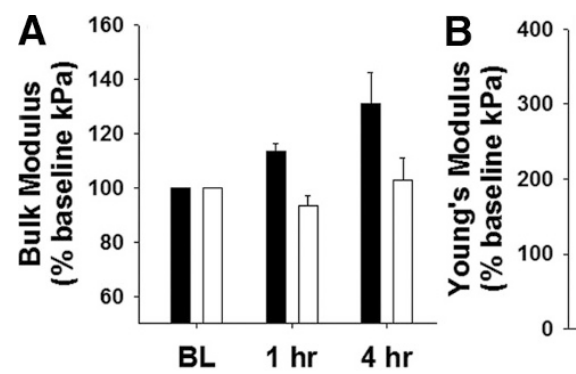

Figure 6. Changes in tracheal stress-strain relationships associated with $4 \mathrm{~h}$ of MV or SHAM. Bulk modulus $(A)$ increased over time in animals exposed to mechanical ventilator pressures $(p<0.05)$ but not SHAM. Elastic modulus $(B)$ increased over time in ventilated animals $(p<0.05)$. * significant effect for time $(p<0.05) ; \ddagger$ significant effect for group $(p<0.01)$.

\section{DISCUSSION}

In this study, we evaluated the relationship between the time course of airway injury resulting from typical mechanical ventilator pressure waveforms and trauma response/tissue modeling proteins. We have shown that HSP-70 and MMP2 and 9 are produced by tracheal tissue and secreted into the airway lumen as a result of mechanical distention of the airway. Furthermore, HSP-70 and MMP-2 secretion peaked early (within $1 \mathrm{~h}$ ) in the time course of the initiation of pressure exposure. In this regard, HSP-70 secretion profile was associated with the secretion profile for MMP-2, and thus may be related to the tissue remodeling response secondary to airway trauma.
HSP-70 appears to be a sensitive marker of injury in the airway as even mild trauma from instrumentation and measurements in this study may have resulted in a degree of HSP-70 secretion in our sham animals. To obtain pressure volume data to calculate elastic properties, the sham airways were exposed to static stretch at each hourly interval. It is noteworthy, that this static stretch most likely resulted in HSP-70 secretion from the sham airways despite no change in mechanical properties or secretion of measured proteins. The higher PIP used in this study ensures physical injury was produced in the trachea and allows correlation with HSP-70 as a marker of injury. Our group plans to use lower and more clinically relevant PIP in future studies. A crucial point is the rapid time course of HSP-70 secretion, i.e., within the first hour of trauma to the airway tissues. Reports of the time course of HSP-70 kinetics associated with injury to other tissues indicate that HSP-70 typically does not appear until after a few hours (30). In the current study, this early HSP-70 appearance is associated with MMP-2 secretion, which also peaked within the first hour of injury and is attenuated following the spike in HSP-70. It is difficult to interpret the rapid elevation in HSP-70. This could represent an earlier spike (before the first hour) in HSP-70 (not measured in our study) and therefore, may represent an acute response to the physical stress experienced by tracheal tissue in response to MV. The fall in HSP-70 after the first hour would also support that HSP-70 is secreted or produced early and acutely in response to injury. Although we did not note a difference in tracheal 
tissue content of HSP-70 between ventilated animals and SHAM when harvested at the $4 \mathrm{~h}$ interval, we hypothesize that if tracheal tissue was harvested and analyzed within the first hour of MV, tissue content of HSP-70 between the groups would have been different and may correspond with tracheal aspirate HSP-70 secretions pattern. A limitation of this study is the single time duration $(4 \mathrm{~h})$, which the animals were exposed to MV. Proteases like MMPs 2 and 9 can degrade and cleave components of extracellular matrix in response to various factors such as physical stress (31). The cleaved matrix fragments and nonmatrix substances can act as inflammatory mediators contributing to further inflammation and tissue remodeling (32). MMPs 2 and 9 have been shown to play a role in lung branching and alveoralization via interaction between MMP and inflammatory mediators $(17,18)$. Therefore, it is speculated that MMPs may play a role in airway tissue remodeling after physical stress.

HSP-70 is also known to function as a molecular chaperone activated by cellular stress, which helps to attenuate inflammation by stabilizing inhibitory kappa B $(\mathrm{I} \kappa \mathrm{B})$. This prevents activation of $\mathrm{NF} \kappa \mathrm{B}$ and subsequent downstream genes for inflammatory mediators (26). HSPs interact with the MAP (mitogen-activated protein) kinase pathways by a balanced inhibition of both extracellular signal-regulated kinase (ERK) and Jun N-terminal kinase (JNK). Transcription of HSPs in turn is regulated by MAP kinase. Both may be important factors affecting balance between cell death and survival programs $(33,34)$. The role of MMPs in tissue remodeling and therefore, cell death and survival, after physical stress may be associated with the MAP kinase pathways as well. Unfortunately, the available $\mathrm{NF} \kappa \mathrm{B}$ assays were not compatible with ovine tissues and therefore, we were unable to evaluate the interaction between $\mathrm{HSP}-70$ and $\mathrm{NF} \kappa \mathrm{B}$.

The interactions between HSP-70 and MMPs, and their relationship to airway trauma, have not been fully elucidated. Our data indicates that HSP-70 is secreted by tracheal tissues in response to injury and may play a role in regulating the response to airway injury. The significant and early response of trauma-related and tissue-modeling proteins associated with mechanical ventilator induced injury of the upper airway has important clinical and further research implications. Ongoing and future studies are aimed at further evaluating the interaction between trauma-response mediators, tissue proliferation pathways and airway remodeling.

Acknowledgments. We acknowledge Barbara E. Gray, B.A., CPM, Administrative Manager, Nemours Research Lung Center, for her contribution to the research effort.

\section{REFERENCES}

1. Greenspan JS, Shaffer TH, Fox WW, Spitzer AR 2004 Fetal and Neonatal Physiology. 3rd ed. Philadelphia: Saunders, pp 961-978

2. McFawn PK, Mitchell HW 1997 Bronchial compliance and wall structure during development of the immature human and pig lung. Eur Respir J 10:27-34

3. Deoras KS, Wolfson MR, Searls RL, Hilfer SR, Shaffer TH 1991 Developmental changes in tracheal structure. Pediatr Res 30:170-175

4. Panitch HB, Deoras KS, Wolfson MR, Shaffer TH 1992 Maturational changes in airway smooth muscle structure-function relationships. Pediatr Res 31:151-156

5. Shaffer TH, Bhutani VK 1980 Alterations in bulk modulus of tracheae during development. Respiration 39:344-350
6. Bhutani VK, Rubenstein D, Shaffer TH 1981 Pressure-induced deformation in immature airways. Pediatr Res 15:829-832

7. Bhutani VK, Shaffer TH 1981 Effect of intermittent positive pressure application on the bulk modulus of the developing rabbit trachea. Respiration 41:192-198

8. Bhutani VK, Ritchie WG, Shaffer TH 1986 Acquired tracheomegaly in very preterm neonates. Am J Dis Child 140:449-452

9. Deoras KS, Wolfson MR, Bhutani VK, Shaffer TH 1989 Structural changes in the tracheae of preterm lambs induced by ventilation. Pediatr Res 26:434-437

10. Bhutani VK, Shaffer TH, Abbasi S, Spitzer AR, Fox WW 1986 Effect of high-frequency jet ventilation on preterm and rabbit tracheal mechanics. Pediatr Pulmonol 2:327-331

11. Miller TL, Touch SM, Shaffer TH 2006 Matrix metalloproteinase and tissue inhibitor of matrix metalloproteinase expression profiles in tracheal aspirates do not adequately reflect tracheal or lung tissue profiles in neonatal respiratory distress: observations from an animal model. Pediatr Crit Care Med 7:63-69

12. Atkinson JJ, Senior RM 2003 Matrix metalloproteinase-9 in lung remodeling. Am J Respir Cell Mol Biol 28:12-24

13. Ekekezie II, Thibeault DW, Simon SD, Norberg M, Merrill JD, Ballard RA, Ballard PL, Truog WE 2004 Low levels of tissue inhibitors of metalloproteinases with a high matrix metalloproteinase-9/tissue inhibitor of metalloproteinase-1 ratio are present in tracheal aspirate fluids of infants who develop chronic lung disease. Pediatrics 113:1709-1714

14. Miller TL, Altman AR, Tsuda T, Shaffer TH 2006 An ultrasound imaging method for in vivo tracheal bulk and Young's moduli of elasticity. J Biomech 40:1615-1621

15. Miller TL, Zhu Y, Altman AR, Dysart K, Shaffer TH 2007 Sequential alterations of tracheal mechanical properties in the neonatal lamb: effect of mechanical ventilation. Pediatr Pulmonol 42:141-149

16. McQuibban GA, Gong JH, Wong JP, Wallace JL, Clark-Lewis I, Overall CM 2002 Matrix metalloproteinase processing of monocyte chemoattractant proteins generates CC chemokine receptor antagonists with anti-inflammatory properties in vivo. [comment]. Blood 100:1160-1167

17. Ganser GL, Stricklin GP, Matrisian LM 1991 EGF and TGF alpha influence in vitro lung development by the induction of matrix-degrading metalloproteinases. Int J Dev Biol 35:453-461

18. Kheradmand F, Rishi K, Werb Z 2002 Signaling through the EGF receptor controls lung morphogenesis in part by regulating MT1-MMP-mediated activation of gelatinase A/MMP2. J Cell Sci 115:839-848

19. Baluk P, Raymond WW, Ator E, Coussens LM, McDonald DM, Caughey GH 2004 Matrix metalloproteinase-2 and -9 expression increases in Mycoplasma-infected airways but is not required for microvascular remodeling. Am J Physiol Lung Cell Mol Physiol 287:L307-L317

20. Vreugdenhil HA, Haitsma JJ, Jansen KJ, Zijlstra J, Plotz FB, Van Dijk JE, Lachmann B, Van Vught H, Heijnen CJ 2003 Ventilator-induced heat shock protein 70 and cytokine mRNA expression in a model of lipopolysaccharide-induced lung inflammation. Intensive Care Med 29:915-922

21. Villar J, Mendez-Alvarez S 2003 Heat shock proteins and ventilator-induced lung injury. Curr Opin Crit Care 9:9-14

22. Asea A, Kraeft SK, Kurt-Jones EA, Stevenson MA, Chen LB, Finberg RW, Koo GC, Calderwood SK 2000 HSP70 stimulates cytokine production through a CD14dependant pathway, demonstrating its dual role as a chaperone and cytokine. Nat Med 6:435-442

23. Baldwin AS Jr 1996 The NF-kappa B and I kappa B proteins: new discoveries and insights. Annu Rev Immunol 14:649-683

24. Beere HM 2004 "The stress of dying": the role of heat shock proteins in the regulation of apoptosis. J Cell Sci 117:2641-2651

25. Lee KH, Lee CT, Kim YW, Han SK, Shim YS, Yoo CG 2005 Heat shock protein 70 negatively regulates the heat-shock-induced suppression of the IkappaB/NFkappaB cascade by facilitating IkappaB kinase renaturation and blocking its further denaturation. Exp Cell Res 307:276-284

26. Yoo CG, Lee S, Lee CT, Kim YW, Han SK, Shim YS 2000 Anti-inflammatory effect of heat shock protein induction is related to stabilization of I kappa B alpha through preventing I kappa B kinase activation in respiratory epithelial cells. J Immunol 164:5416-5423

27. Ghosh S, May MJ, Kopp EB 1998 NF-kappa B and Rel proteins: evolutionarily conserved mediators of immune responses. Annu Rev Immunol 16:225-260

28. Miller TL, Blackson TJ, Shaffer TH, Touch SM 2004 Tracheal gas insufflationaugmented continuous positive airway pressure in a spontaneously breathing model of neonatal respiratory distress. Pediatr Pulmonol 38:386-395

29. Miller TL, Shashikant BN, Pilon AL, Pierce RA, Shaffer TH, Wolfson MR 2005 Effects of an intratracheally delivered anti-inflammatory protein (rhCC10) on physiological and lung structural indices in a juvenile model of acute lung injury. Biol Neonate 89:159-170

30. Gabai VL, Sherman MY 2002 Invited review: interplay between molecular chaperones and signaling pathways in survival of heat shock. J Appl Physiol 92:1743-1748

31. Parks WC, Shapiro SD 2001 Matrix metalloproteinases in lung biology. Respir Res 2:10-19

32. Danan C, Jarreau PH, Franco ML, Dassieu G, Grillon C, Abd Alsamad I, Lafuma C, Harf A, Delacourt C 2002 Gelatinase activities in the airways of premature infants and development of bronchopulmonary dysplasia. Am J Physiol Lung Cell Mol Physiol 283:L1086-L1093

33. Beere HM 2005 Death versus survival: functional interaction between the apoptotic and stress-inducible heat shock protein pathways. J Clin Invest 115:2633-2639

34. Vliagoftis H, Schwingshackl A, Milne CD, Duszyk M, Hollenberg MD, Wallace JL, Befus AD, Moqbel R 2000 Proteinase-activated receptor-2-mediated matrix metalloproteinase-9 release from airway epithelial cells. J Allergy Clin Immunol 106:537-545 